\title{
PROJETO SEMENTE: PROPOSTA PARA O CENTRO COMUNITÁRIO DO QUILOMBO RIO DOS MACACOS
}

PROYECTO SEMILLA: CENTRO COMUNITARIO DO QUILOMBO RIO DOS MACACOS

THE SEED PROJECT: COMUNITARY CENTER OF QUILOMBO RIO DOS MACACOS

\section{OLIVEIRA, LUANA FIGUEIREDO DE CARVALHO}

Arquiteta e Urbanista, Especialista em Habitação e Direito a Cidade, Mestranda em Arquitetura e Urbanismo, Sócia Fundadora do Atelier Plural. E-mail: Ifigueiredo.arq@gmail.com

\section{RAMOS, JOÃO MAURÍCIO}

Arquiteto e Urbanista, Mestre em Educação e Doutorando em Arquitetura e Urbanismo, Professor da FAUFBA. E-mail: ramosjsm@hotmail.com

\section{VELAME, FÁBIO MACEDO}

Arquiteto e Urbanista, Mestre e Doutor em Arquitetura e Urbanismo, Professor da FAUFBA. E-mail: velame.fabio@gmail.com

\section{INTRODUÇÃO}

O Projeto Semente: Centro Comunitário do Quilombo Rio dos Macacos foi o resultado do processo participativo de Assistência Técnica de Arquitetura e Urbanismo, prestado em 2014 à comunidade do Quilombo Rio dos Macacos em Simões Filho, Região Metropolitana de Salvador, cuja proposta de projeto arquitetônico foi desenvolvida na etapa final de conclusão da Residência Profissional.1

A experiência foi desenvolvida inicialmente em âmbito multidisciplinar com uma equipe formada por uma arquiteta, um urbanista e uma geógrafa, utilizando o Etnomapeamento como ferramenta teórico e metodológica para diagnosticar as demandas da comunidade e auxiliar no fortalecimento da organização comunitária e posteriormente no âmbito individual da assistência técnica em arquitetura.

O processo de desenvolvimento deste projeto buscou qualificar o projeto arquitetônico com sua inserção no contexto social, político e étnico, entendendo a realidade de usos do lugar por meio das relações cotidianas; tenciona-se criar não apenas o espaço físico, mas também um ponto simbólico dentro do território, referência de autoafirmação, autonomia e luta da comunidade.

\section{ETNOMAPEAMENTO E DIRETRIZES COLETIVAS}

O trabalho de elaboração da cartografia teve início com a aproximação durante o processo de audiências públicas com o governo Federal, prestando assistência técnica à comunidade Quilombola de Rio dos Macacos $^{2}$ na compreensão das propostas apresentadas pela Secretaria da República e Ministério da Defesa. Assim, a partir da necessidade de aprofundamento no tema da cartografia foi realizado um Etnomapeamento ${ }^{3}$, a fim de compreender melhor as relações territoriais específicas e complexas de um Quilombo contemporâneo ${ }^{4}$, fundamental para o entendimento das dinâmicas espaciais, questões étnicas e sociais, norteadoras do desenvolvimento futuro do projeto arquitetônico.

Ao partir da escala macro das relações territoriais trabalhadas no âmbito coletivo, para chegar na escala e materialidade do elemento comunitário, foi necessária a contínua aproximação com a geografia e a cartografia quilombola, com objetivo de compreender melhor a formação e as relações espaciais desses territórios étnicos. 
O território é uma condição essencial, porque define o grupo humano que o ocupa, onde estão localizados e porque estão naquele espaço (historicidade). A terra (o terreiro) não significa apenas uma dimensão física, mas antes de tudo um espaço comum, ancestral, de todos que temos registros de história, da experiência pessoal e coletiva do seu povo, uma instância do trabalho concreto e das vivências do passado e do presente. [...] uma instância de uso comum-coletivo, que é o elemento principal da consolidação do território étnico, da manutenção da identidade cultural e da coesão social (ANJOS, 2011, p.85).

A escolha de um Centro Comunitário como objeto para desenvolvimento do projeto arquitetônico foi definida em conjunto com a Comunidade, a partir das diretrizes do diagnóstico territorial coletivo, sendo primeiramente compreendidas as relações espaciais desejadas entre o Centro Coletivo e o Território. O difícil momento de fragilidade e fragmentação enfrentado pela comunidade $^{5}$, com a permanente ameaça de expulsão pela Marinha do Brasil nas últimas décadas, necessita uma construção/edificação forte, que demarque a luta e afirme a ocupação da terra e, ao mesmo tempo, reúna a comunidade.

A construção de um espaço verdadeiramente coletivo acontece naturalmente, consolidado pelo uso cotidiano, especialmente em uma comunidade de hábitos rurais, cujos espaços coletivos se formam normalmente em torno das atividades produtivas, como a casa de farinha, hortas coletivas, viveiros de animais, etc. Portanto a localização e construção do centro se tornou o foco inicial dos debates com a comunidade, sem perder de vista a premissa da garantia da propriedade da terra.

Figura 1: Mapa de Localização e Rede de Espaços Coletivos

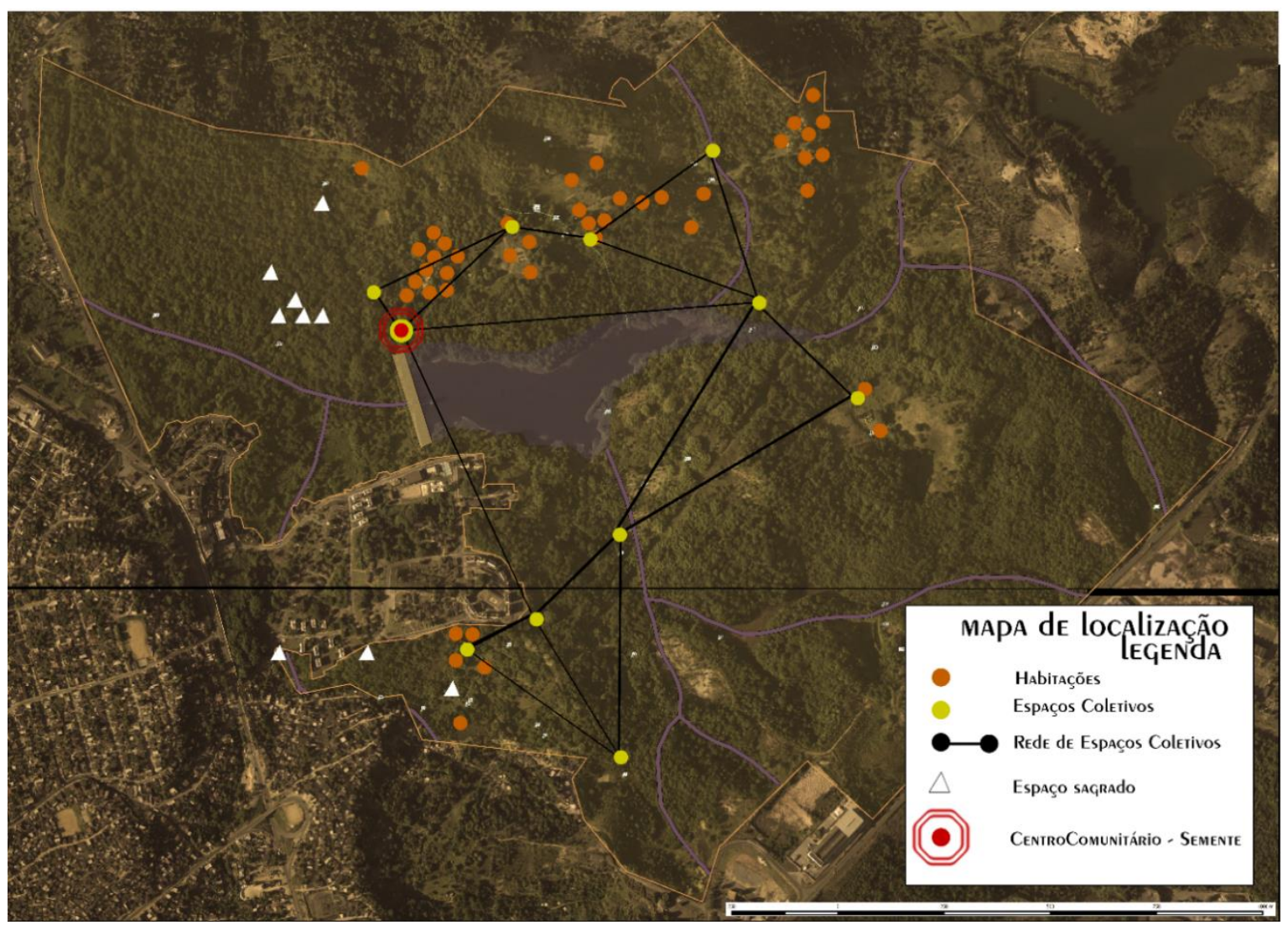

Fonte: Elaborado pela autora, OLIVEIRA 2015

Importante mencionar a prioridade da questão de segurança e proteção do território diante da perspectiva de abertura da comunidade para a comunicação urbana direta, não mais intermediada pela Marinha. A visibilidade e proteção das áreas produtivas e habitacionais requerem cuidados extras, e o posicionamento do centro permite uma boa visão da estrada principal, a ser construída na parte norte do território. A construção e implementação de diversos outros espaços coletivos é muito importante para que a rede esteja em funcionamento, e possa garantir a coesão territorial.

A questão Quilombola originalmente está conectada ao território. A consolidação da sua relação com a terra e a água é elemento fundamental para seu modo de fazer e viver, sendo estas as bases do conceito da 
semente, adotado nesse projeto, que entende a esperança e a busca pela autonomia como uma característica dos quilombos, assim como a construção de raízes no território, como sua autoafirmação.

Durante o processo participativo foram levantadas as demandas da comunidade e, com isso, montado o programa de necessidades do centro a ser construído, agrupados em 4 eixos de organização comunitária, que seguem as mesmas diretrizes do trabalho coletivo:

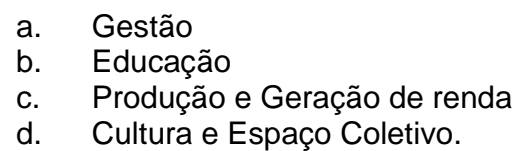

Os usos e atividades identificados foram agrupados nos 4 eixos de organização comunitária, tendo como seus principais objetivos:

- Definição do centro comunitário com diversas atividades afins, como mais um passo da estruturação comunitária;

- Núcleo embrionário de organização da gestão e produção da comunidade (Autonomia e Geração de renda);

- Apoio e afirmação política da Associação de Moradores (ARQM-Associação dos Remanescentes de Quilombo Rio dos Macacos);

- Consolidação de uma Estrutura Física Coletiva (Marco da demarcação e titulação da Terra);

- Símbolo de Luta e Resistência (Marco/Símbolo, Elementos ancestrais e atuais).

\section{PROJETO SEMENTE: PROJETO ARQUITETÔNICO PARTICIPATIVO}

A população estimada da comunidade Quilombola Rio dos Macacos era de 70 famílias de acordo com as inscrições no Relatório Técnico de Identificação e Delimitação - RTID, 2013. Atualmente residem no território 24 famílias, com 42 casas (aproximadamente 120 pessoas); Área estimada do território: $301 \mathrm{ha}$; Área titulada em 2015: 104 ha; Área total estimada do centro comunitário: Aprox. 500m². ${ }^{6}$

O maior desafio do processo participativo foi definir coletivamente o significado do centro comunitário para a comunidade e para o arquiteto. Com esse objetivo foram realizadas oficinas para o desenvolvimento do projeto do centro comunitário, mantendo a metodologia do conhecimento compartilhado, baseada na pedagogia de Paulo Freire. Foram desenvolvidas 04 oficinas, partindo da escala do mapa, sempre traçando um paralelo com a realidade do território, para a dimensão do uso cotidiano e o espaço potencial que este local poderá ser:

Oficina O que Queremos: Definição dos produtos individuais por especialidade técnica;

Oficina de Localização/Definição Programática/Estudo Preliminar;

Oficina de Tamanho e Escala: Analise do Pré-Dimensionamento do Centro;

Oficina de Aprovação: Estudo Preliminar/Maquete;

Figura 2 e 3: Fotos das Oficinas de Projeto

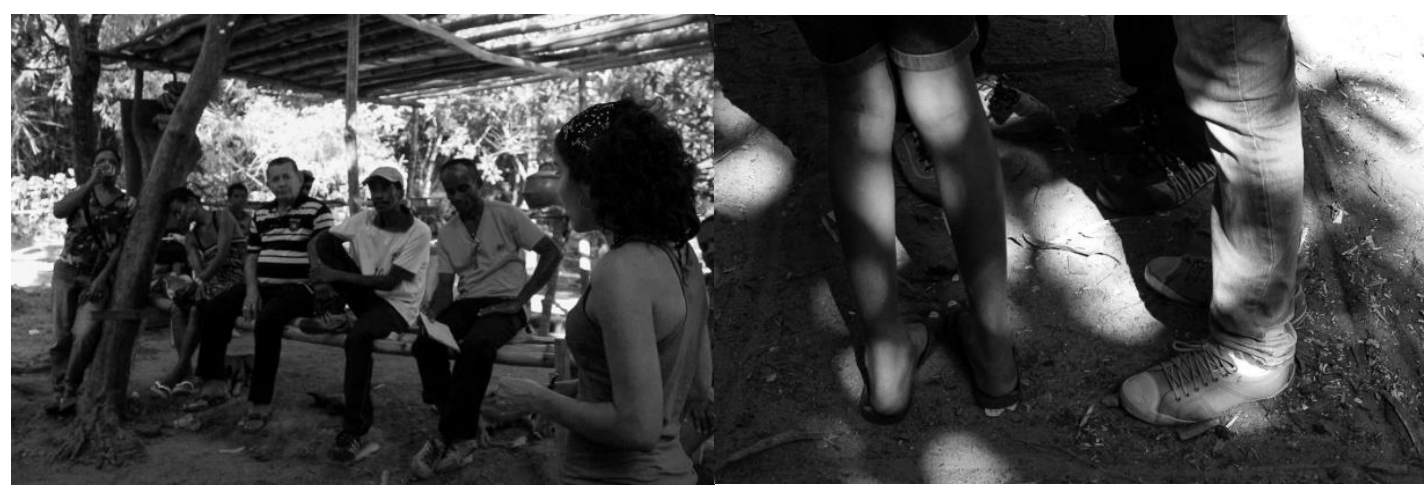

Fonte: Acervo da autora, OLIVEIRA 2015. 
Figura 4 e 5: Fotos das Oficinas de Projeto

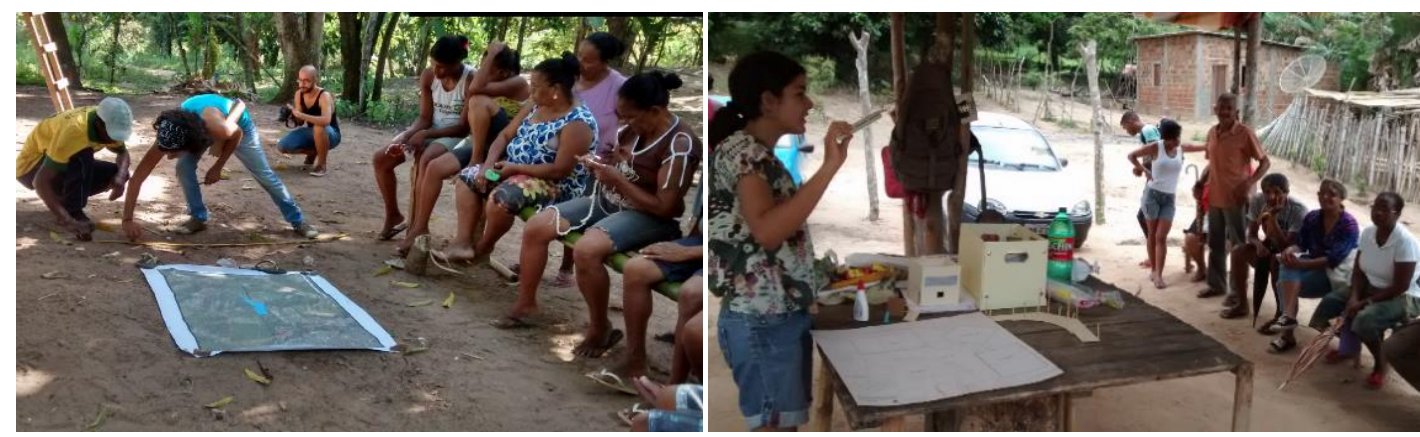

Fonte: Acervo da autora, OLIVEIRA 2015.

As oficinas foram realizadas com os objetivos de: levantar o programa de necessidades; definir as prováveis localizações do Centro Comunitário no território; estabelecer comparativos de escalas, entre os hectares (ha) trabalhados nas oficinas de cartografia coletiva e esclarecer noções de $\mathrm{m}^{2}$ para o projeto de arquitetura; desenvolver o pré-dimensionamento da construção para os usos solicitados; realizar teste dos usos e escala humana com uma maquete 1/50, para aprovação do Estudo Preliminar; realizar uma estimativa de custo versus dimensões definidas e a partir dos custos definir possíveis etapas construtivas; realiza roda de diálogo sobre o significados e nome do Centro Comunitário.

Figura 6: Imagens da Maquete - Oficina de Escala Humana
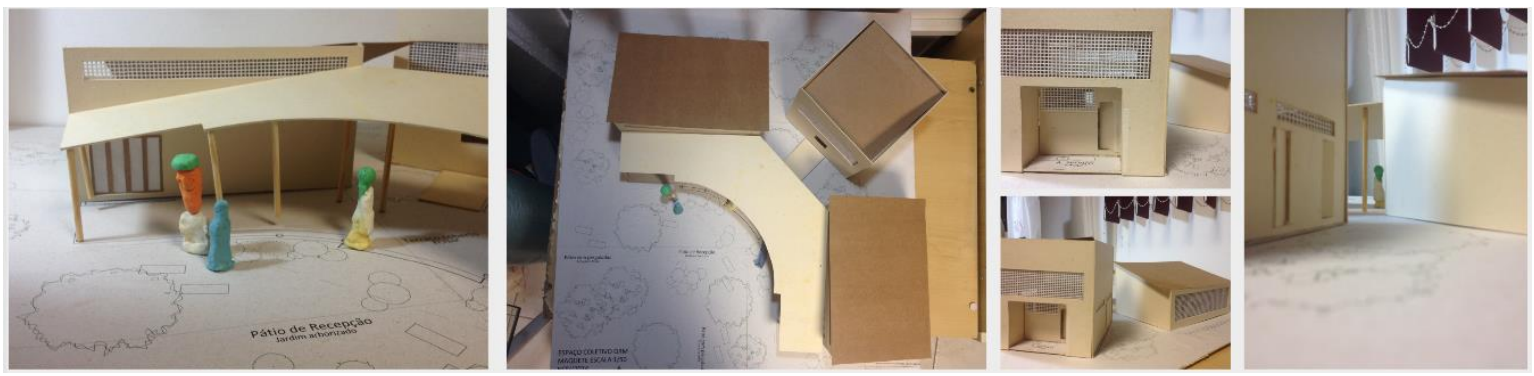

Fonte: Acervo da autora, OLIVEIRA 2015.

Foi realizado um pré-dimensionamento a partir da quantidade de pessoas que residem no território, para que primeiro a comunidade consolide o uso e a aplicação do conceito da unidade como semente e, de fato, realize as atividades de gestão, educação e produção. Posteriormente poderá ser realizada uma ampliação da construção de acordo com as demandas e necessidades da comunidade. As Atividades a serem desenvolvidas se organizam nos 4 eixos de organização comunitária, divididas em Módulos:

O Módulo 01, Gestão, em vermelho, abriga a sede da associação comunitária, secretaria e depósito. Local para encontros com as diversas assessorias e parceiros, reuniões e atendimento médico (agentes de saúde).

O Módulo 02, Educação, em amarelo, abriga uma grande sala de aula, multiuso, atendendo as crianças, em diversos turnos, a adultos em turmas profissionalizantes, inclusão digital e troca de experiências.

O Módulo 03, Produção e Economia, em azul, possui uma cozinha comunitária, apoio para a produção agrícola e ao beneficiamento das matérias primas (doces, polpas, etc.). Este módulo é um apoio às demais estruturas, possuindo instalações sanitárias com chuveiro, oferecendo suporte a estadia de visitantes.

O Módulo 04, Uso Coletivo e Cultural, não constitui uma edificação, mas a configuração de uma praça, roda de capoeira e espaços de convivência e feira ao ar livre. 


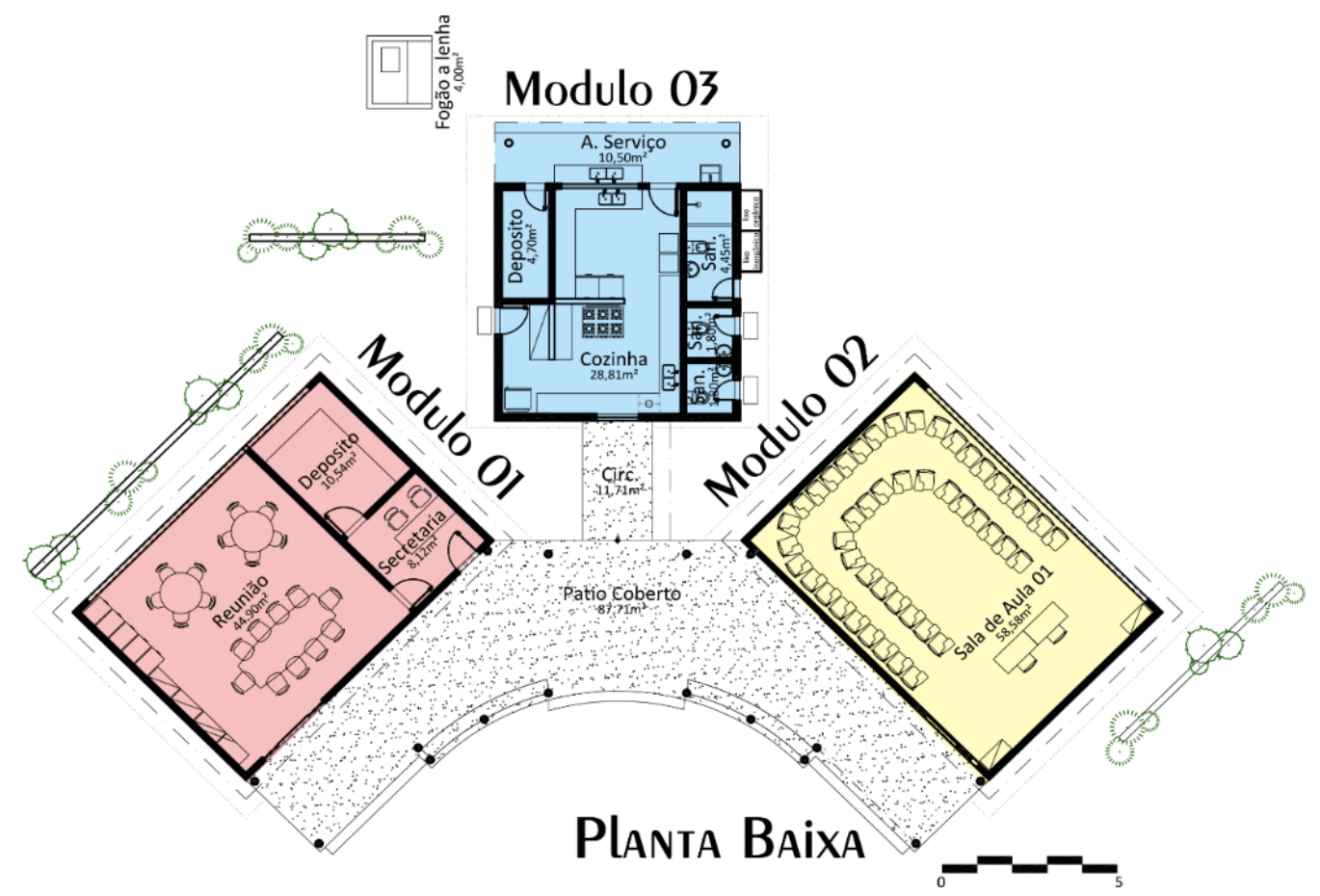

Fonte: Acervo da autora, OLIVEIRA 2015.

O espaço a ser construído é como um texto, um discurso transmissor de mensagens a serem lidas e decifradas, a forma arquitetônica e a intenção do desenho influenciam diretamente nas relações humanas incentivando ou evitando o encontro. Dessa forma, o projeto se desenha como uma condição em potencial para as atividades humanas, se concretizando com o uso real feito pelas pessoas.

Tanto a sua localização e como a implantação das edificações na área escolhida, busca um posicionamento estratégico, onde se possa ter uma boa visibilidade do território e contribuir com a organização da segurança e controle de entrada.

A forma circular do Pátio Coberto, aberta em uma das quinas, é um convite ao encontro (Espaço Público), um lugar para recepcionar os visitantes da comunidade. A escolha dos Módulos com uma forma arquitetônica simples e implantados de maneira simétrica com núcleo circular e radial busca uma facilidade na sua execução. A definição de volumes construtivos independentes é para que a obra possa ser executada em Etapas, a partir da viabilidade econômica da comunidade.

Propõe-se que, para configurar um símbolo de autonomia e resistência do território, a escolha dos materiais de construção seja definida juntamente com a comunidade. O projeto aponta dois caminhos a seguir: 1 . Materiais de construção convencionais, encontrados no mercado ou 2. Materiais de construção sustentáveis, bioarquitetura, com levantamento das potencialidades de materiais e técnicas tradicionais de autoconstrução do território.

Ainda se indica que as Fachadas sejam objeto de novas oficinas especificas em especial com as Mulheres e seu artesanato tradicional e a Juventude quilombola, para a criação de símbolos de referência da identidade e cultura do centro.

A proposta é que a área do centro seja um grande palco para atividades que possibilitam multiplicar o senso coletivo, e estimular a troca de saberes e conhecimentos, desejando que a comunidade possa desenvolver experimentalmente no centro comunitário oficinas e técnicas de diversas áreas de interesse, como arquitetura, agricultura, geração de renda, capacitações, entre inúmeras outras a serem realizadas parcerias com grupos e outras comunidades. 
Figura 8: Planta de Situação do Centro Comunitário

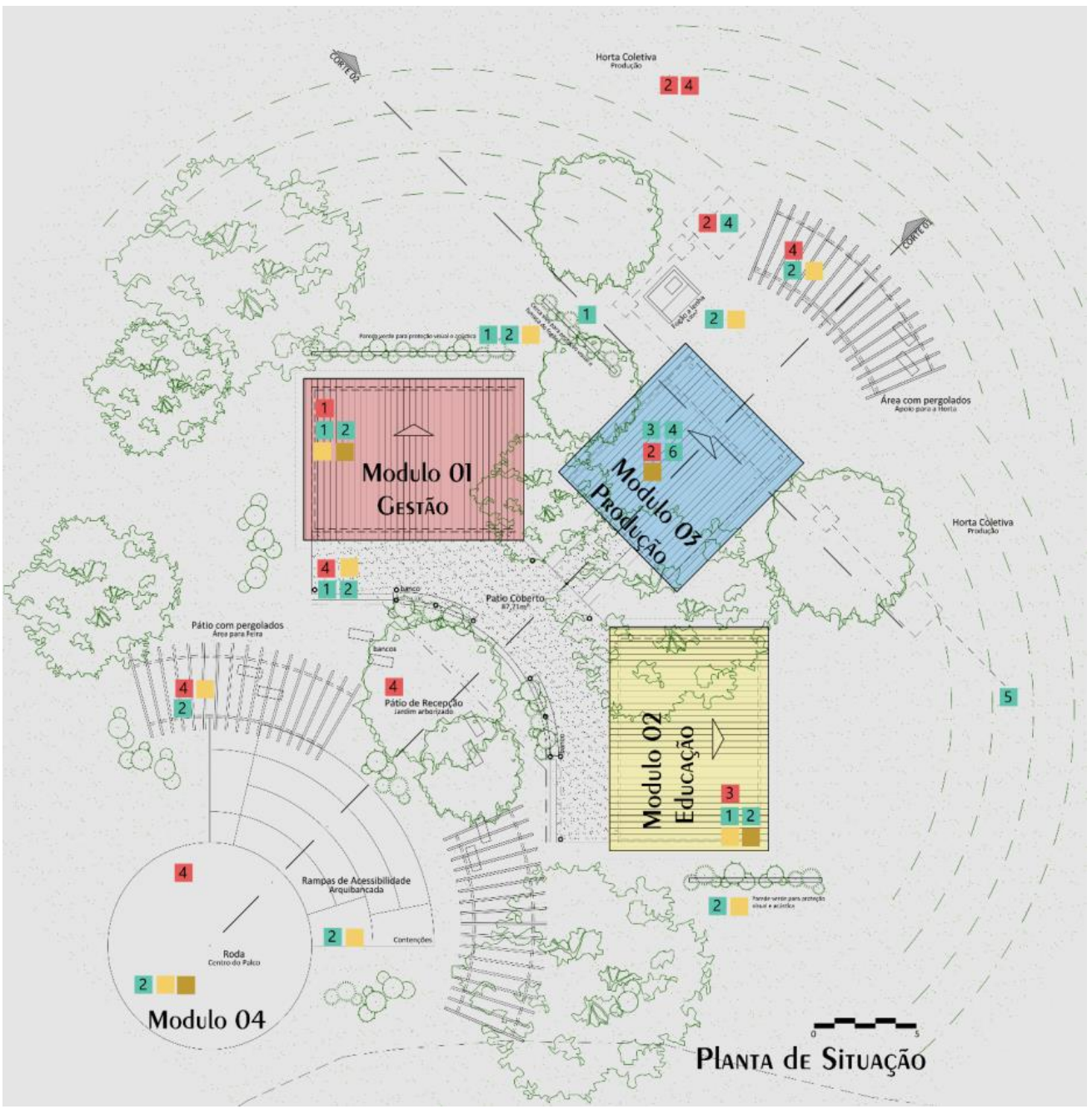

Fonte: Acervo da autora, OLIVEIRA 2015.

\section{CONSIDERAÇÕES FINAIS}

Atualmente, a comunidade do Quilombo Rio dos Macacos continua em luta para adquirir o direito ao uso livre das suas terras, e se faz emergente a implementação de políticas e programas sociais, econômicos, de infraestrutura e habitação, a fim de auxiliar a reestruturação dessa comunidade com uma trajetória de privações e difícil sobrevivência.

A localização do centro comunitário no território e sua justificativa foram destacadas pois apenas a construção do centro não garante que este desempenhe o papel desejado nas relações espaciais da comunidade. A reconstrução de uma vida coletiva passa pela necessidade de articulação e organização comunitária, fortemente desenvolvido nos últimos anos, através da militância política da comunidade.

Acreditamos que o centro comunitário, consiste em um espaço em potencial para o fortalecimento da comunidade. A intenção é que este novo espaço seja uma semente, uma contribuição, na restruturação espacial (física); política, social e econômica da comunidade, incentivando o seu desenvolvimento, crescimento, manutenção e permanência naquele território (OLIVEIRA, 2015, p.19).

Os meios para a execução do mesmo, estão atrelados não apenas à questão jurídica do território ainda por se definir; mas também a questões políticas e recursos públicos. Existe a possibilidade de financiamento parcial ou total da obra por entidades privadas, como a Coordenadoria Ecumênica de Serviço - CESE ou 
outras entidades de apoio, e ainda a organização das etapas construtivas a ser desenvolvidas em sistema de mutirão, com a esperança e a expectativa de que seja viabilizado para fortalecer a cultura quilombola.

\section{REFERÊNCIAS}

ANJOS, Rafael Sanzio Araújo dos. Cartografia e Quilombos: territórios étnicos africanos no Brasil. Africana Studia, n. 9, p. 337-355, 2006.

OLIVEIRA, Luana F. Projeto Semente: Centro Comunitário do Quilombo Rio dos Macacos. 2014. 74f. Monografia (Especialização) - Faculdade de Arquitetura e Urbanismo, Universidade Federal da Bahia, Salvador, 2014.

SEPPIR. Plano Nacional de Desenvolvimento Sustentável dos Povos e Comunidades Tradicionais de Matriz Africana 2013-2015. 2013.

INSTITUTO NACIONAL DE COLONIZAÇÃO E REFORMA AGRÁFIA. Relatório Técnico de Identificação e Delimitação do Território da Comunidade Quilombola de Rio dos Macacos. Salvador: IGEO, 2013.

\section{NOTAS}

${ }^{1}$ Este artigo tem como base o Trabalho Final desenvolvido no Curso de Especialização em Assistência Técnica e Direito a Cidade, na modalidade Residência Profissional em Arquitetura, Urbanismo e Engenharia (Residência AU+E/UFBA), tendo como tutores os profs. Me. João Maurício Ramos e Dr. Fabio Macedo Velame (OLIVEIRA, 2014). Os diagnósticos e oficinas foram desenvolvidos pela equipe formada, além da autora, pelos Residentes Paula Regina Cordeiro, geógrafa e Leonardo Polli, urbanista.

${ }^{2}$ Em 2011, a comunidade se organizou em torno das políticas afirmativas do Estado e obtiveram a certificação de auto reconhecimento quilombola, Certidão de Comunidade Remanescente de Quilombo - CRQ, emitida pela Fundação Cultural Palmares - FCP. Sob pressão de diversas manifestações e visibilidade nacional, em 2012 o Instituto Nacional de Colonização e Reforma Agrária - INCRA, elaborou o Relatório Técnico de Identificação e Delimitação - RTID, da comunidade, caracterizando que "Rio dos Macacos é um quilombo, tendo famílias reconhecidas enquanto remanescentes quilombolas, hereditários de ex-escravos que ali se concentraram há quase cem anos, em antigas fazendas e usinas de açúcar" (INCRA, 2012).

3 “Contemporaneamente, portanto, o termo quilombo não se refere a resíduos ou resquícios arqueológicos de ocupação temporal ou de comprovação biológica. Também não se trata de grupos isolados ou de uma população estritamente homogênea. [...] consistem em grupos que desenvolveram práticas cotidianas de resistência na manutenção e reprodução dos seus modos de vida característicos e na consolidação de um território próprio" (O'DWYER, 1995, p. 02).

${ }^{4}$ Ferramenta teórico metodológica de captação de dados espaciais de grupos étnicos, que viabilizou a coleta dos dados identitários da comunidade em questão, mapeados com gps e cartografados. Ressaltando que a própria população residente, suas memórias e conhecimentos são os elementos fundamentais desse tipo de cartografia, tendo nos técnicos apoio didático e técnico.

${ }^{5}$ A publicação do RTID da Comunidade Quilombola de Rio dos Macacos no Diário Oficial da União, só acontece em agosto de 2014. Em 18 de novembro de 2015, a Portaria 623, declara "como terras da comunidade remanescente de Rio dos Macacos, em Simões Filho (Grande Salvador), uma área de 301 hectares, dos quais somente 104 hectares foram destinados para titulação de posse". Publicação do Diário Oficial da União, no dia 18 de novembro de 2015, disponível em https://www.jusbrasil.com.br/diarios/104483220/dou-secao-118-11-2015-pg-58.

${ }^{6}$ Dados coletados durante o Etnomapeamento desenvolvido durante o curso da Residência Profissional no ano de 2014.

NOTA DO EDITOR (*) O conteúdo do artigo e as imagens nele publicadas são de responsabilidade do(s) autor(es). 